\title{
Bimetallic Ruthenium-Gold-on-Magnesia Catalysts: Chemicophysical Properties and Catalytic Activity
}

\author{
I. W. Bassi, ${ }^{1}$ F. Garbassi, ${ }^{2}$ AND G. VlaiC \\ Istituto Guido Donegani S.p.A., Novara Research Center, Via Fauser 4, 28100 Novara, Italy
}

A. Marzi and G. R. Tauszik

Montedison S.p.A., Bollate Research Center, Via San Pietro 50, 2002I Bollate, Milano, Italy

G. Cocco

Institute of Physical Chemistry, University of Venice, D.D. 2137, 30123 Venezia, Italy

\author{
S. Galvagno ${ }^{3}$ and G. Parravano \\ Department of Chemical Engineering, University of Michigan, Ann Arbor, Michigan 48109
}

Received February 12, 1979; revised January 10, 1980

\begin{abstract}
Bimetallic Ru-Au catalysts supported on $\mathrm{MgO}$ were prepared, their atomic composition varying from $100 \%$ Ru to $100 \% \mathrm{Au}$. Samples were characterized after impregnation and drying at $110^{\circ} \mathrm{C}$ and after further reduction by hydrogen at $400^{\circ} \mathrm{C}$. X-Ray line broadening analysis, small-angle X-ray scattering, transmission electron microscopy, gas chemisorption, diffuse reflectance spectroscopy (DRS), X-ray photoelectron spectroscopy (XPS), and extended X-ray absorption fine structure (EXAFS) analysis were used. Catalytic activity was measured for the oxygen transfer between CO and $\mathrm{CO}_{2}$. The $\mathrm{Ru}$ and $\mathrm{Au}$ precursor compounds appear to be modified, and have probably interacted in the bimetallic samples, already after impregnation and drying. Relevant amounts of metal oxides are found in some "reduced" catalysts; a metal-support interaction is proposed for $\mathrm{Au} / \mathrm{MgO}$. The amounts of the Ru and Au oxidized species found by EXAFS in the examined bimetallic sample are significantly different from those found in $\mathrm{Ru} / \mathrm{MgO}$ and $\mathrm{Au} / \mathrm{MgO}$, respectively. The DR spectra of the bimetallic samples are not a simple combination of those of the monometallic catalysts. The Ru/Au atomic ratios measured by XPS are higher than the analytical ones. The fraction of surface Ru atoms, measured by hydrogen chemisorption, increases on decreasing the bulk $\mathrm{Ru} / \mathrm{Au}$ atomic ratio. The $\mathrm{Au} / \mathrm{MgO}$ sample has an activity which is two orders of magnitude higher than that of the remaining samples. All of this suggests the existence of a $R u$ surface enrichment and also an Ru-Au chemical interaction. These conclusions are also supported by an ir study of $\mathrm{CO}$ chemisorbed on the same samples.
\end{abstract}

\section{INTRODUCTION}

The striking properties of bimetallic catalysts, containing metals which are immiscible in the bulk state, have been pointed out

1 Deceased April 9, 1979.

${ }^{2}$ To whom correspondence should be addressed.

${ }^{3}$ On leave from Istituto Guido Donegani.

${ }^{4}$ Deceased April 1, 1978. by Sinfelt et al. (1-4). In particular, $\mathrm{Ru}-\mathrm{Cu}$ and $\mathrm{Os}-\mathrm{Cu}$ were found to interact in the form of both bimetallic clusters dispersed on a support and unsupported aggregates; the catalytic activity of $\mathrm{Ru}$ and $\mathrm{Os}$ was significantly modified by this interaction.

In this work, we have considered a similar bimetallic system, containing gold instead of copper. Ruthenium and gold are 
again almost immiscible in the bulk state (5). The use of gold is in connection with our previous studies on supported gold catalysts $(6-13)$, which showed that: (i) small gold particles can display an activity comparable to that of platinum (6); (ii) an electronic interaction takes place between gold and support, modifying the metal activity and selectivity (8); (iii) a correlation exists between reaction rate and catalyst composition for $\mathrm{Au}-\mathrm{Pt} / \mathrm{SiO}_{2}$ (9) (Pt being partially miscible with gold).

It appeared therefore of interest to investigate: (a) whether an interaction between two immiscible metals, like that found for $\mathrm{Ru}-\mathrm{Cu}$, can also exist for $\mathrm{Ru}-\mathrm{Au}$, and (b) how this possible interaction could affect the previously studied catalytic activity of gold.

This paper reports the results of the chemicophysical characterization and of catalytic activity tests (in the oxygen transfer reaction between $\mathrm{CO}$ and $\mathrm{CO}_{2}$ ) for some $\mathrm{Ru}-\mathrm{Au} / \mathrm{MgO}$ samples, at various $\mathrm{Ru} / \mathrm{Au}$ atomic ratios. In order to overcome the limitations that affect the various techniques generally used in the characterization of supported metals, and to achieve a picture of these samples as reliable as possible, they were studied by employing in parallel the following techniques: diffuse reflectance spectroscopy (DRS), X-ray photoelectron spectroscopy (XPS), extended X-ray absorption fine structure (EXAFS), wide-angle X-ray scattering (WAXS), small-angle $X$-ray scattering (SAXS), transmission electron microscopy (TEM), and gas chemisorption. A study of the ir spectra of $\mathrm{CO}$ chemisorbed on the same catalysts is reported elsewhere (14).

\section{EXPERIMENTAL}

Commercial hydrated ruthenium trichloride (Rudi Pont $\mathrm{RuCl}_{3} \cdot \mathrm{H}_{2} \mathrm{O}$, reagent grade) and "yellow gold trichloride" $\left(\mathrm{HAuCl}_{4} \cdot 3 \mathrm{H}_{2} \mathrm{O}\right.$, Carlo Erba RPE) were used as precursor compounds. The support material was magnesium oxide (Carlo Erba RPE-ACS); its measured surface area was
$15 \mathrm{~m}^{2} \mathrm{~g}^{-1}$. The $\mathrm{Ru} / \mathrm{MgO}, \mathrm{Au} / \mathrm{MgO}$, and $\mathrm{Ru}-\mathrm{Au} / \mathrm{MgO}$ catalysts were prepared by soaking the support, under stirring, in a freshly prepared aqueous solution of the corresponding salt(s) $\left(400 \mathrm{~cm}^{3}\right.$ solution $/ 100$ $\mathrm{g}$ support). After $12 \mathrm{~h}$, the excess water was removed by filtration and the remaining solid was dried $4 \mathrm{~h}$ at $110^{\circ} \mathrm{C}$. The samples were finally reduced by a purified hydrogen stream $\left(2 \mathrm{~h}\right.$ at $300^{\circ} \mathrm{C}$ and $2 \mathrm{~h}$ at $\left.400^{\circ} \mathrm{C}\right)$. After reduction, samples were stored in air.

DRS spectra were recorded on a PerkinElmer EPS-3T spectrometer, equipped with an integrating sphere. $\mathrm{KCl}$ was used as reference sample. No absorption in the examined wavelength range is due to the $\mathrm{MgO}$ support present in the samples.

$\mathrm{XP}$ spectra were performed in a commercial $\mathrm{PHI}$ instrument, using $\mathrm{MgK} \alpha$ radiation. Targets were prepared from powder samples, by insertion in indium foils (15). The low atomic concentration of the metals and the overlap of support- $\mathrm{Mg}_{2 s}$ and contamination $-C_{1 s}$ peaks on the strongest of the $A u$ and $\mathrm{Ru}$ signals, respectively, complicate the interpretation of the spectra. Quantitative chemical surface analysis was based on XPS peak areas, corrected according to the relative photoelectric cross section (16). Owing to the above-mentioned overlap, the $\mathrm{Ru}_{3 p_{3 / 2}}$ peak was used for quantitative analysis, instead of the stronger $\mathrm{Ru}_{3 d_{5 / 2}}$, which was used for binding energy measurements. Electrostatic charging (affecting the experimental binding energy values) was corrected by means of a flood gun and assuming the $C_{1 s}$ peak at $285.0 \mathrm{eV}$ as reference.

EXAFS experiments were carried out by an X-ray tube (with an Ag target for gold and an Mo target for ruthenium), an $\mathrm{LiF}$ monochromator, and a scintillation counter with pulse height analyzer (17). Samples were mounted in a cell with Mylar windows, kept at $10^{-5}$ Torr $(1$ Torr $=133.3 \mathrm{~N}$ $\mathrm{m}^{-2}$ ) and at liquid-nitrogen temperature for the duration of the experiments. Ru powder (Baker) and $\mathrm{RuO}_{2}$ (Johnson Matthey), mixed with silica (Aerosil 600, Degussa) and pelletized, were used as reference sam- 
ples for ruthenium; the literature values of Au metal, $\mathrm{HAuCl}_{4} \cdot 3 \mathrm{H}_{2} \mathrm{O}$, and $\mathrm{Au}_{2} \mathrm{O}_{3}(11)$ were used for gold. Examined absorption edges were $\mathrm{L}_{\text {III }}$ for gold and $K$ for ruthenium; 10 runs through the absorption edge were averaged to obtain the desired statistics (17). Data elaboration was performed according to the method proposed by Lytle et al. $(11,18)$. By comparison with crystallographic data $(19,20), 0.27$ and 0.32 phase shift values were chosen for the first coordination sphere of metallic $\mathrm{Ru}$ and $\mathrm{RuO}_{2}$, respectively.

WAXS diagrams were recorded by a Philips X-ray powder diffractometer, equipped with a scintillation counter and a pulse height analyzer. Ni-filtered $\mathrm{CuK} \alpha$ radiation was used. The method employed for line broadening analysis is based on the $K \alpha_{1} \alpha_{2}$ doublet correction and on the correction for instrumental broadening, according to Ref. (21); Scherrer's equation was then applied to the pure diffraction profile. The $\mathrm{Ru}(110)$ and $\mathrm{Au}(220)$ reflections were used for the analysis.

TEM photomicrographs were taken on carbon extractive replicas, by a Philips EM-300 instrument. Particle dispersion was calculated by a semiautomatic method, using a Zeiss TGZ 33 counter and an appropriate program for computer elaboration (22).

SAXS curves were recorded using a Kratky camera aligned to obtain the "infinite" beam condition and equipped with an electronic programmed step scanner. Ni-filtered $\mathrm{Cu} K \alpha$ radiation, with a pulse height discriminator, was used. For the determination of the absolute scattering intensity, the primary beam intensity was measured by means of a Lupolen standard sample (23). No significant effect of the "pore maskant" $(24,25)$ on the catalystsupport difference curves was found, the $\mathrm{MgO}$ particles being practically free of porosity. A more detailed description of the method followed for the SAXS experiments is reported elsewhere (26).

For the chemisorption and reaction rate measurements, the samples were pressed into wafers and then crushed; the fraction 25-40 mesh was then treated (in situ) as follows: $1 \mathrm{~h} / 250^{\circ} \mathrm{C} / 70$ Torr air, reduced 1 $\mathrm{h} / 400^{\circ} \mathrm{C} / 70$ Torr $\mathrm{H}_{2}$, evacuated 0.5 $\mathrm{h} / 450^{\circ} \mathrm{C}$, and finally cooled to the wanted temperature.

The oxygen transfer between $\mathrm{CO}$ and $\mathrm{CO}_{2}$ was studied in an all-glass recycle reaction system, comprising evacuation train, storage vessels, reactor, recycle glass pump, and Geiger proportional counter (FDI-Tracer Laboratories). An SC-90 Utility scaler with an SC-42A Dual Timer was employed to amplify and record the counting. Research-grade $\mathrm{CO}_{2}(>99.998 \%), \mathrm{CO}$ $(>99.997 \%)$, and $\mathrm{H}_{2}(>99.9995 \%)$ were introduced into the storage bulbs after distillation $\left(\mathrm{CO}_{2}\right)$ or after passage through a liquid-nitrogen trap $\left(\mathrm{CO}\right.$ and $\left.\mathrm{H}_{2}\right)$. Radioactive $\mathrm{CO}_{2}$ (New England Nuclear Corp.), labeled with carbon-14 isotopc, was employed without further purification and mixed with the $\mathrm{CO}+\mathrm{CO}_{2}$ mixtures. Details of the experimental system used have been given previously (10). All runs were performed at a constant 42 Torr $\mathrm{CO}$ partial pressure. No reaction was found to take place on the reactor walls or on the catalyst support.

Chemisorption experiments were performed in a conventional all-glass static system. Volumes of chemisorbed gas were calculated from the change in the gas pressure. The dead-space volume was measured with helium. $\mathrm{H}_{2}$ chemisorption on $\mathrm{Ru}$ and $\mathrm{Ru}-\mathrm{Au}$ samples was performed at $100^{\circ} \mathrm{C}$, in the $30-400$ Torr pressure range, while $\mathrm{O}_{2}$ chemisorption on $\mathrm{Au}$ was determined at $200^{\circ} \mathrm{C}$ in the $0.2-0.7$ Torr pressure range. $\mathrm{H}_{2}$ and $\mathrm{O}_{2}$ uptakes were measured after the reaction tests.

\section{RESULTS}

The chemical composition of the samples, measured by atomic absorption (27), is reported in Table 1 . The results were used to specify the catalysts by symbols representing the approximate value of the 
TABLE 1

Weight and Atomic Compositions of the $\mathrm{Ru}-\mathrm{Au} / \mathrm{MgO}$ Catalysts

\begin{tabular}{|c|c|c|c|c|c|c|c|c|c|c|}
\hline \multirow[t]{3}{*}{ Catalyst $^{a}$} & \multicolumn{4}{|c|}{$\begin{array}{l}\text { Analysis by atomic absorption } \\
\text { (reduced catalysts) }\end{array}$} & \multicolumn{6}{|c|}{ Analysis by X-ray photoelectron spectroscopy } \\
\hline & & & & & \multicolumn{3}{|c|}{$\begin{array}{l}\text { Atom\%, } \\
\text { reduced catalysts }\end{array}$} & \multicolumn{3}{|c|}{$\begin{array}{c}\text { Atom\%, } \\
\text { unreduced catalysts }\end{array}$} \\
\hline & $\mathbf{R u}$ & $\mathrm{Au}$ & $\mathbf{R u}$ & $\mathrm{Au}$ & $\mathbf{R u}$ & $\mathrm{Au}$ & $\mathrm{Cl}$ & $\mathbf{R u}$ & $\mathrm{Au}$ & $\mathrm{Cl}$ \\
\hline R100 & 4.44 & - & 0.9 & - & 0.4 & - & 0.8 & 1.3 & - & 2.6 \\
\hline R089 & 3.48 & 0.81 & 0.7 & 0.09 & 0.2 & - & 0.8 & & & \\
\hline R064 & 2.12 & 2.34 & 0.4 & 0.2 & 0.5 & - & 1.4 & 0.5 & - & 0.6 \\
\hline $\mathrm{R}^{2} 6 \mathrm{I}^{\mathrm{c}}$ & 2.36 & 2.97 & 0.5 & 0.3 & 0.7 & 0.1 & 2.7 & 0.2 & - & 1.7 \\
\hline R047c & 1.25 & 2.70 & 0.3 & 0.3 & 0.5 & 0.1 & - & 0.3 & Traces & - \\
\hline R010 & 0.26 & 4.45 & 0.05 & 0.5 & - & 0.2 & 1.2 & & & \\
\hline R000 & - & 3.46 & - & 0.4 & - & 0.2 & - & - & 0.2 & - \\
\hline
\end{tabular}

${ }^{a}$ Catalyst symbols represent the approximate value of: $100 \times$ (number of Ru atoms)/(number of Ru and Au atoms), on the basis of the atomic absorption analysis.

${ }^{b}$ Calculated from the atomic absorption data, assuming that the support has exactly the stoichiometric MgO composition.

c These samples were prepared subsequently, to check some features of reflectance spectra, and therefore were only partially characterized by other techniques.

$\mathbf{R u} /(\mathbf{R u}+\mathrm{Au})$ atomic percentage: thus, e.g., R061 is a sample in which a value of about $61 \mathrm{Ru} /(\mathrm{Ru}+\mathrm{Au})$ atom\% was found.

\section{Diffuse Reflectance Spectroscopy}

The DR spectra were run both before and after reduction, so as to obtain information on the chemistry of the $\mathrm{Ru} / \mathrm{MgO}, \mathrm{Ru}-$ $\mathrm{Au} / \mathrm{MgO}$, and $\mathrm{Au} / \mathrm{MgO}$ systems (Fig. 1). To keep Fig. 1 simple, the spectrum of only one bimetallic sample is reported.

After impregnation of the support and drying at $110^{\circ} \mathrm{C}$, the $\mathrm{DR}$ spectra of $\mathrm{R} 100$ and $\mathrm{R} 000$ are different from those of the respective precursors $\left(\mathrm{RuCl}_{3} \cdot \mathrm{H}_{2} \mathrm{O}\right.$ and $\mathrm{HAuCl}_{4} \cdot 3 \mathrm{H}_{2} \mathrm{O}$ ). The spectrum of $\mathrm{R000}$ shows a weak band at about $540 \mathrm{~nm}$, which could be due to some finely dispersed gold (see later). The spectra of R089 and R010 are similar to those of $\mathrm{R} 100$ and $\mathrm{R} 000$, respectively, but, in the $R 010$ sample, the $540-\mathrm{nm}$ band is no longer evident (even if R010 has a greater gold content than R000). $A$ band at $410 \mathrm{~nm}$ is the main feature of the R064, R061, and R047 spectra, which are not at all a simple combination of those of the monometallic samples.
After reduction, the colors of R000 and R010 turn to dark violet (from white with some pink shade and from pale yellow, respectively); correspondingly, a strong absorption maximum is found at about 540 $\mathrm{nm}$. The most obvious attribution is that this band corresponds to some dispersion

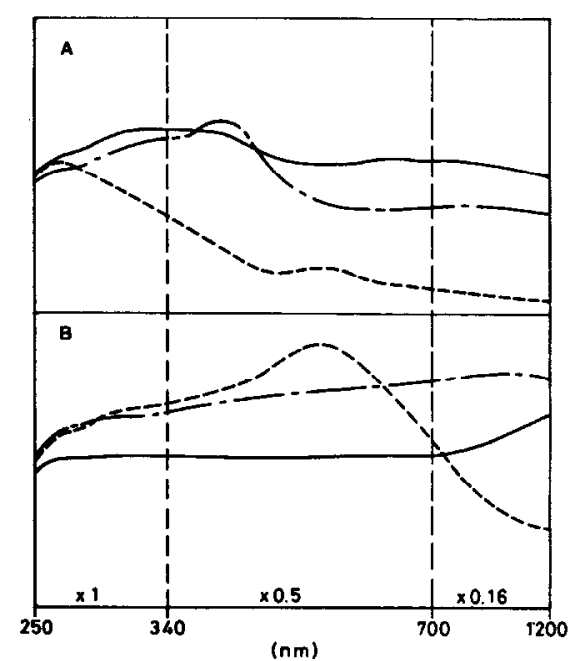

FIG. 1. Diffuse reflectance spectra (absorbance mode, arbitrary units) of samples R100 (-), R064 (--), and R000 (--). (A) Before reduction; (B) after reduction. 
state of metallic gold; black, ruby, and purple colors are in fact reported for finely divided gold. Reduced R100, R089, R064, R061, and R047 are gray (each with a different shade); their DR spectra are flat and tend to very large absorption maxima, in the 600 - to $1000-\mathrm{nm}$ range for $\mathrm{R} 064$, $\mathrm{R} 061$, and R047, beyond $1200 \mathrm{~nm}$ for R100 and R089. Thus, the physical and/or chemical nature of the scattering surface of these samples seems to be affected by the $\mathrm{Ru} / \mathrm{Au}$ ratio and, as already found for the unreduced samples, the spectra of the bimetallic R064, R061, and R047 catalysts are not a simple combination of those of $\mathrm{Ru} / \mathrm{MgO}$ and $\mathrm{Au} / \mathrm{MgO}$.

\section{X-Ray Photoelectron Spectroscopy}

The surface composition is reported in Table 1; for most of the samples, XP spectra were also run before reduction. In the almost equiatomic catalysts (R064, R061, and $\mathrm{R} 047$ ), the $\mathrm{Ru} / \mathrm{Au}$ atomic ratio found by XPS is higher than the analytical one, or else the Au peak is not even observed. As the $\mathrm{MgO}$ particles are practically free of microporosity, different distributions of the two metals into the support pores (such as to affect the measured $\mathrm{Ru} / \mathrm{Au}$ ratio) can be excluded. Therefore, the above results could suggest a ruthenium surface enrichment. A significant chlorine contamination of the catalyst surface is also observed in most samples, even after reduction by hydrogen. No systematic effect of this last treatment on the surface composition is found.

Whenever the $\mathrm{Au}_{4 f_{7 / 2}}$ peak was detectable, a binding energy (BE) value (83.4 $83.7 \mathrm{eV}$ ) corresponding to that of metallic gold was found, even before reduction. This can be due to a decomposition of the gold compounds under the $\mathrm{X}$-ray beam (28). The $\mathrm{Ru}_{3 d_{3 / 2}}(\mathrm{BE}=280.1-280.7 \mathrm{eV})$ instead is always intermediate between those of $\mathrm{RuO}_{2}(279.7 \mathrm{eV})$ and $\mathrm{RuO}_{3}(281.1$ $\mathrm{eV}$; Ru metal, $279.0 \mathrm{eV}$; $\mathrm{RuCl}_{3}, 281.6 \mathrm{eV}$ ); therefore, ruthenium oxidized species are present even in the reduced samples, at least in that surface layer actually observed by XPS.

\section{Extended X-Ray Absorption Fine Structure}

When conventional X-ray sources are used (instead of a synchrotron source), data collection is very slow. Therefore, only the most representative catalysts (R100, R064, and $R 000)$ and two reference samples (Ru and $\mathrm{RuO}_{2}$ ) were examined by the EXAFS technique (Fig. 2).

EXAFS shows that ruthenium is mainly in the metallic state in R100, even though some $\mathrm{Ru}-\mathrm{O}$ interactions seem to be present (peaks at 1.80 and $2.95 \AA$ ). Metallic Ru prevails also in sample R064, but there is a significant amount of $\mathrm{Ru}-\mathrm{O}$ bonds with a radial distance corresponding to the first coordination shell of $\mathrm{RuO}_{2}$. On the basis of the EXAFS data, however, it is not possible to establish whether these $\mathrm{Ru}-\mathrm{O}$ bonds are due to a partial oxidation of the metal clusters, owing to the contact with the atmosphere, and/or to the interaction with the oxygen atoms of the support. Only metallic gold is found in sample R064. On the contrary, in sample $\mathrm{R} 000, \mathrm{Au}-\mathrm{O}$ bonds, like those found in $\mathrm{Au}_{2} \mathrm{O}_{3}$ (peak at $1.75 \AA$ ), are indicated by EXAFS, together with metallic gold; furthermore, the magnitude of the peak at $2.19 \AA$ is too high to be attributed only to a $p-s$ transition and could suggest the existence of $\mathrm{Au}(\mathrm{I})-\mathrm{O}$ bonds $(11,12)$. As a relevant reoxidation, due to the contact with the atmosphere after the reduction treatment, is much less likely for supported gold than for supported ruthenium, the most straightforward interpretation of the EXAFS data is that some gold interacts with the support. The results obtained for sample R000 are in agreement with those previously found by EXAFS on different $\mathrm{Au} / \mathrm{MgO}$ preparations (11).

The first-shell average coordination number (calculated from the crystallite size measured by WAXS and assuming a spherical model for the metal particles) is about 

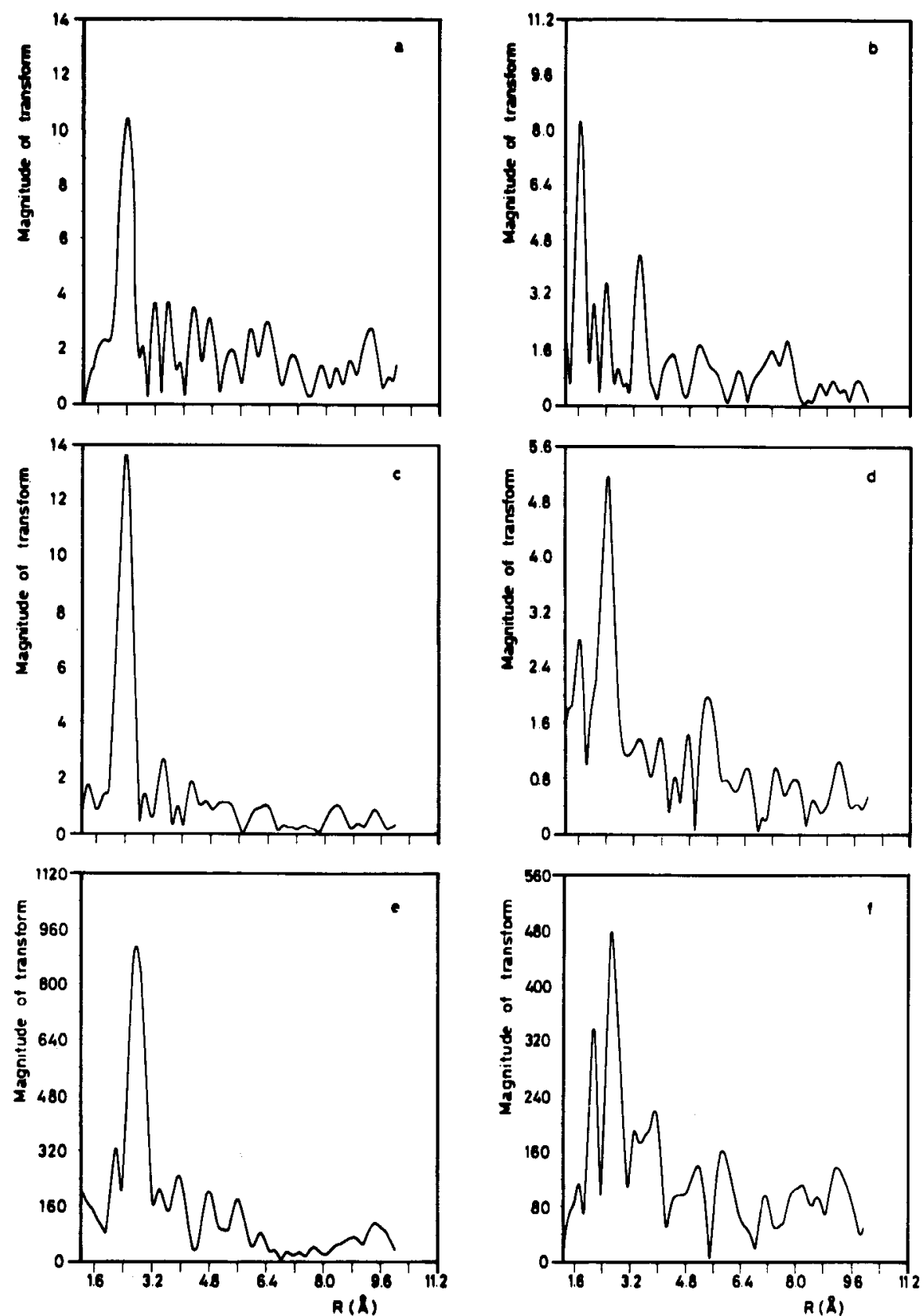

FIG. 2. Magnitude of the Fourier transforms of $\chi(k)$, plotted vs the radial distance (in $\AA$ ) from the absorbing atoms (Ru or Au). (a) Ru metal (powder); (b) $\mathrm{RuO}_{2}$; (c) $\mathrm{R} 100$; (d) $\mathbf{R 0 6 4}$ (absorbing atom = Ru); (e) R064 (absorbing atom = Au); (f) R000.

11 for $\mathrm{Au}$ in sample R064. That calculated from the EXAFS data, according to Ref. (11), is 10.9, which confirms that gold in sample R064 is almost exclusively in the metallic state. This conclusion is furthermore supported by the fact that a $2.4 \mathrm{wt} \%$ gold content was measured by WAXS (with the internal standard method), the analyti- 
TABLE 2

Metal Particle Average Size $(\bar{d})$ and Other Data from WAXS, TEM, SAXS, and Chemisorption Measurements

\begin{tabular}{|c|c|c|c|c|c|c|c|c|}
\hline \multirow[t]{2}{*}{ Sample } & \multicolumn{2}{|c|}{ WAXS } & \multirow{2}{*}{$\begin{array}{l}\text { TEM } \\
\bar{d}(\AA)\end{array}$} & \multicolumn{2}{|c|}{ SAXS } & \multicolumn{3}{|c|}{ Chemisorption } \\
\hline & $\begin{array}{c}\mathbf{R u}(110) \\
\hat{d}(\AA)\end{array}$ & $\begin{array}{c}\mathrm{Au}(220) \\
\bar{d}(\AA)\end{array}$ & & $\begin{array}{l}\text { Porod } \\
\text { diameter } \\
(\AA)\end{array}$ & $\begin{array}{c}\text { Metal } \\
\text { surface } \\
\text { area } \\
\left(\mathrm{m}^{2} \mathrm{~g}^{-1}\right)\end{array}$ & $\begin{array}{c}\text { Gas uptake } \\
\left(\mathrm{cm}^{3} \text { (STP)/g cat.) }\right. \\
\times 10^{2}\end{array}$ & $\bar{d}(\AA)$ & $\begin{array}{l}\text { Fraction of } \\
\text { Ru atoms on } \\
\text { the surface } \\
\end{array}$ \\
\hline $\mathbf{R} 100$ & 144 & - & 71 & 66 & 75 & $35.0^{b}$ & 129 & 0.071 \\
\hline R089 & 155 & 550 & 77 & 79 & 62 & $30.5^{b}$ & $c$ & 0.079 \\
\hline R064 & n.d. & 265 & 78 & 125 & 31 & $23.5^{b}$ & $c$ & 0.100 \\
\hline R061 & n.d. & 387 & & & & & & \\
\hline R047 & n.d. & 315 & & & & & & \\
\hline R010 & n.d. & 335 & 61 & 43 & 72 & $4.2^{b}$ & $c$ & 0.146 \\
\hline R000 & - & n.d. & 83 & 39 & 79 & $12.1^{d}$ & 91 & - \\
\hline
\end{tabular}

${ }^{a}$ Calculated by assuming a constant $\mathrm{Ru} / \mathrm{H}=1$ stoichiometry.

${ }^{b}$ Hydrogen at $100^{\circ} \mathrm{C}$.

c The average size cannot be estimated from chemisorption data in the bimetallic samples.

${ }^{d}$ Oxygen at $200^{\circ} \mathrm{C}$.

cal value being $2.34 \%$. The first-shell coordination number calculated from the EXAFS data for Au in sample R000 is 5.7. According to the average particle size obtained by SAXS (Au was in fact not detectable by WAXS in this sample), the coordination number should be about 8.3 . The comparison between these values suggests that about $70 \%$ of the total gold is in the metallic form in R000. The calculation of ruthenium coordination numbers in $R 100$ and R064 is not possible by EXAFS. In fact, the calculation (11) involves the magnitude of the first-shell peak of the $\mathrm{Ru}$ powder standard, which in our case is lowered by a partial oxidation of the sample (of course, this oxidation does not prevent the use of this specimen as a reference for the interpretation of radial distances in the Fourier transform obtained for the examined catalysts).

\section{Metal Dispersion}

WAXS, TEM, and SAXS (Porod diameter, $D_{\mathrm{p}}$, and metal surface area) data are reported in Table 2; the log-normal particlesize distribution curves, calculated from the SAXS parameters, are reported in Fig. 3. Only by WAXS was it possible to distinguish between ruthenium and gold, while TEM and SAXS analyses were performed considering the two metals as a single phase. Taking into consideration that WAXS line-broadening analysis can lose most of the smallest crystallites' contribution in the tail of the diffraction peak, while TEM and SAXS are much more sensitive to

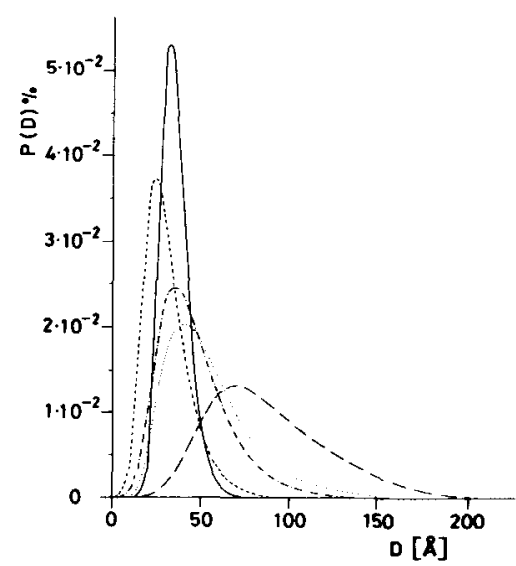

FIg. 3. Particle size distribution curves (by SAXS). R000 (-), R010 (---), R064 (---), R089 ( …), R100 (-·) . 
small particles (even if, when applying the TEM counting method, the amount of particles below $30 \AA$ can be easily underestimated), the disagreement between the data obtained by different techniques can be explained. A more detailed comparison of the SAXS, WAXS, and TEM analyses on some of these samples is reported in Ref. (26). No systematic effect of the Ru/Au ratio on the metal dispersion appears from these data.

$\mathrm{H}_{2}$ chemisorption experiments were performed using conditions similar to those previously described by Taylor (29). The total $\mathrm{H}_{2}$ uptake was calculated by extrapolating the isotherms to zero pressure. No hydrogen chemisorption could be detected on the support and on R000 (gold-only sample). In this last catalyst, metal dispersion was determined by $\mathrm{O}_{2}$ chemisorption at $200^{\circ} \mathrm{C}(13)$. The average particle diameter was calculated for the monometallic samples, from the $\mathrm{H}_{2}$ and $\mathrm{O}_{2}$ uptake values, assuming: (a) $\mathrm{Ru} / \mathrm{H}=1$ and $\mathrm{Au} / \mathrm{O}=2$ stoichiometries; (b) 9.03 and $9.13 \AA^{2}$ for the areas occupied by one $\mathrm{Ru}(29)$ and one $\mathrm{Au}$ (30) atom, respectively. Results of the chemisorption experiments are reported in Table 2. The average particle size obtained from $\mathrm{O}_{2}$ chemisorption for sample $\mathrm{R} 000$ is in good agreement with the TEM datum. Surprisingly enough the value obtained by chemisorption for $\mathrm{R} 100$ is significantly larger than those found by SAXS and TEM, while a better agreement is found with the WAXS datum. Even so, a very close $\mathrm{H}_{2}$ uptake value $\left(0.3 \mathrm{~cm}^{3}{ }_{\text {(STP) }} \mathrm{g}^{-1}\right.$ at $\left.100^{\circ} \mathrm{C}\right)$ was also found on sample R100 (fresh catalyst) in another laboratory, using somewhat different pretreatment conditions $\left(400^{\circ} \mathrm{C}, 2\right.$ $\mathrm{h} / \mathrm{H}_{2}+2 \mathrm{~h} /$ vacuum) (30).

As the actual situation of the metal clusters in the bimetallic samples is not known, obviously their average particle size cannot be derived only from the amount of hydrogen chemisorbed on the $\mathrm{Ru}$ atoms. However, assuming that the $\mathrm{Ru} / \mathrm{H}$ stoichiometry does not change with the $\mathrm{Ru} / \mathrm{Au}$ ratio, one can calculate the fraction of $\mathrm{Ru}$ atoms

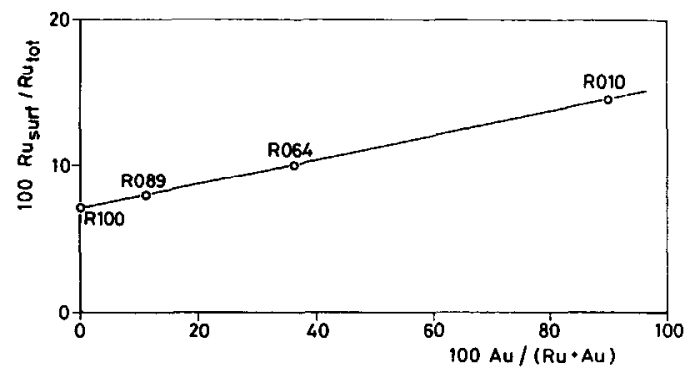

FIG. 4. Percentage of Ru exposed atoms (from the $\mathrm{H}_{2}$ chemisorption results) vs the bulk atomic relative percentage of $\mathrm{Au}$.

exposed on the surface: this value increases on decreasing the $\mathrm{Ru}$ atomic percentage, with a linear dependence (Fig. 4). On sample $\mathrm{R} 064, \mathrm{H}_{2}$ chemisorption was measured before and after reaction tests; since the hydrogen uptake did not change (within $\pm 5 \%$ ), the possibility of a surface enrichment of $\mathrm{Ru}$ atoms, due to the $\mathrm{CO}-\mathrm{CO}_{2}$ reaction mixture, can be ruled out.

\section{$\mathrm{CO}-\mathrm{CO}_{2}$ Oxygen Transfer Experiments}

According to the reaction scheme:

$$
\begin{array}{ll}
{ }^{14} \mathrm{CO}_{2}(\mathrm{~g}) & \rightarrow{ }^{14} \mathrm{CO}(\mathrm{g})+\mathrm{O}(\mathrm{s})(\mathrm{Ia}) \\
{ }^{12} \mathrm{CO}(\mathrm{g})+\mathrm{O}(\mathrm{s}) & \rightarrow{ }^{12} \mathrm{CO}_{2}(\mathrm{~g}) \quad(\mathrm{Ib}) \\
{ }^{12} \mathrm{CO}(\mathrm{g})+{ }^{14} \mathrm{CO}_{2}(\mathrm{~g}) \rightarrow{ }^{14} \mathrm{CO}(\mathrm{g})+{ }^{12} \mathrm{CO}_{2}(\mathrm{~g})
\end{array}
$$

(where $\mathrm{g}$ refers to the gas phase and $\mathrm{s}$ to the catalytic surface), and neglecting isotopic effects on the kinetics, it follows that the reaction rates of (Ia) and (Ib) are equal and can be obtained directly from the rate of reaction $(\mathrm{I})(6,31)$, which is given by

$$
\frac{\mathrm{N}}{A} \frac{\mathrm{dn}\left({ }^{14} \mathrm{CO}\right)}{d t}=k_{\mathrm{c}} p\left({ }^{14} \mathrm{CO}_{2}\right)-k_{\mathrm{c}}^{\prime} p\left({ }^{14} \mathrm{CO}\right) \text {, }
$$

where $N$ is the Avogadro number, $A$ the number of metal atoms, $n\left({ }^{14} \mathrm{CO}\right)$ the number of ${ }^{14} \mathrm{CO}$ moles formed, and $k_{\mathrm{c}}$ and $k_{\mathrm{c}}^{\prime}$ the rate coefficients of forward- and reversereaction steps, respectively. Integration of Eq. (1) gives:

$k_{\mathrm{c}}=\frac{V}{A R T t_{\mathrm{c}}} \frac{1}{(1+\beta)} \ln \frac{1}{1-\alpha(1+\beta)}$, 


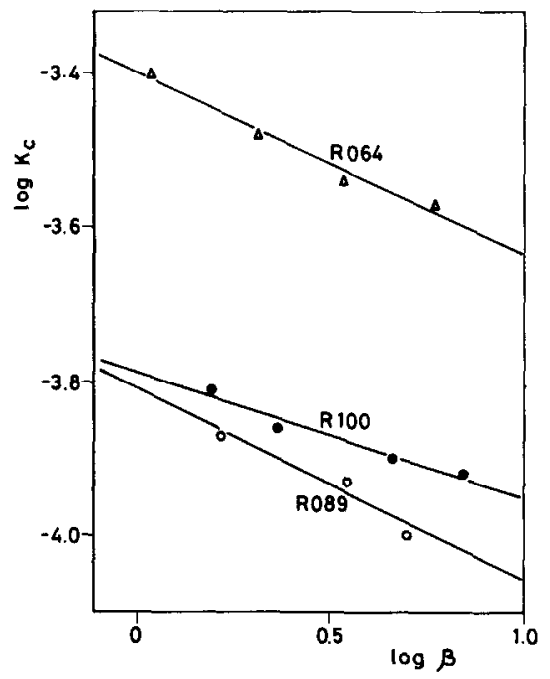

Fig. 5. Influence of $\beta$ on the rate coefficient for reaction (I), at $290^{\circ} \mathrm{C}$.

where $V$ is the volume of the reactor, $t_{\mathrm{c}}$ the contact time, $T$ the absolute temperature, $R$ the gas constant, $\beta$ the $p\left(\mathrm{CO}_{2}\right) / p(\mathrm{CO})$ ratio, and $\alpha$ the $p\left({ }^{14} \mathrm{CO}\right) / p_{i}\left(\mathrm{CO}_{2}\right)$ ratio $\left(p_{\mathrm{i}}\right.$ being the initial pressure). At constant temperature, the rate coefficient is generally dependent upon $\beta$ and can be analytically formulated as:

$$
k_{\mathrm{c}}=k_{\mathrm{c}}^{0} \beta^{m} .
$$

The rate constant $k_{\mathrm{c}}{ }^{0}$ and the coefficient $m$ can be calculated from the experimental data according to Eq. (3); a typical plot of $k_{\mathrm{c}}$ experimental values, as a function of $\beta$, is shown in Fig. 5. Estimated errors are $\pm 15 \%$ for $k_{\mathrm{c}}$ and $\pm 5 \%$ for $m$. No change in the reaction rate was detected by varying the circulation rate in the reactor. Rate constant, exponent $m$, and activation energy values, calculated at $290^{\circ} \mathrm{C}$, are reported in Table 3 . The influence of the bulk composition on the rate constant is shown in Fig. 6.

\section{DISCUSSION}

Before discussing the results obtained on the bimetallic $\mathrm{Ru}-\mathrm{Au} / \mathrm{MgO}$ catalysts, we shall briefly consider those concerning the $\mathrm{Ru} / \mathrm{MgO}$ (R100) and $\mathrm{Au} / \mathrm{MgO}$ (R000) samples. Both DR and XP spectra of the un-
TABLE 3

Rate Constant $k_{c}{ }^{0}$ (Eq. (3)), Exponent $m$ (Eq. (3)), and Activation Energy $E_{\mathrm{a}}$, for Reaction (I) Catalyzed by $\mathrm{Ru}-\mathrm{Au} / \mathrm{MgO}$ Samples, at $290^{\circ} \mathrm{C}$

\begin{tabular}{lrcc}
\hline Sample & $k_{\mathrm{c}}{ }^{0} \times 10^{4 a}$ & $m$ & $E_{\mathrm{a}}{ }^{b}$ \\
\hline R100 & 1.70 & -0.19 & 55 \\
R089 & 1.53 & -0.22 & 51 \\
R064 & 3.89 & -0.24 & 58 \\
R010 & 0.62 & -0.21 & 49 \\
R000 & 110.45 & -0.78 & 9.7
\end{tabular}

${ }^{a}$ Molecules $\mathrm{s}^{-1} \mathrm{~atm}^{-1}$ (metal atom) ${ }^{-1}$.

${ }^{b}$ kcal mole ${ }^{-1}$.

reduced R100 sample show that the precursor compound is modified after impregnation and drying, which is probably due to hydrolysis of $\mathrm{RuCl}_{3}$. A precise identification of the compound(s) present in the catalyst after drying was not achieved; nevertheless, the $\mathrm{Ru}_{3 d_{5 / 2}} \mathrm{BE}$ is near to that reported for $\mathrm{RuO}_{3}$.

EXAFS and WAXS indicate that the hydrogen treatment at $400^{\circ} \mathrm{C}$ reduces ruthenium to the metallic state in sample $R 100$, but EXAFS also suggests the existence of some $\mathrm{Ru}-\mathrm{O}$ interaction, in agreement with the surface analysis by XPS. According to the ir work (14) (a well-reduced surface was found when R100 was kept under hydrogen after the reduction treatment), a surface reoxidation due to contact with the atmosphere seems the most likely explanation of this last result, even though some $\mathrm{Ru}-\mathrm{MgO}$ interaction cannot be excluded (32).

DR and XP spectra indicate the existence

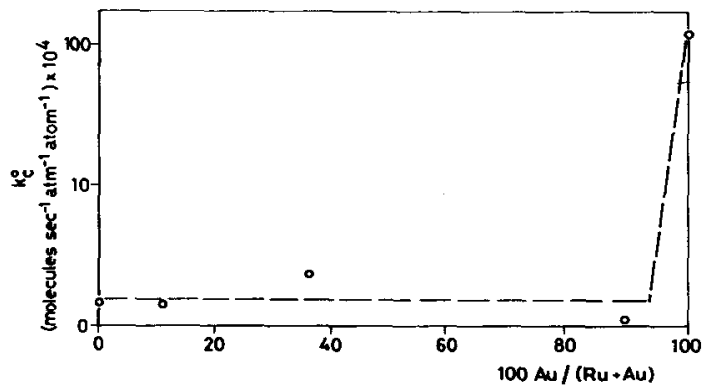

FIG. 6. Rate constant of reaction (I) over $\mathrm{Ru}-$ $\mathrm{Au} / \mathrm{MgO}$ catalysts vs the bulk atomic relative percentage of $\mathrm{Au}$. 
of metallic gold in sample R000, even after drying at $110^{\circ} \mathrm{C}$, thus suggesting a partial decomposition of the precursor compound; probably the presence of hydroxyl groups on the $\mathrm{MgO}$ surface and the hydrothermal conditions of the drying treatment can cause a partial decomposition already at $110^{\circ} \mathrm{C}$.

In the reduced R000 catalyst, EXAFS shows that a relevant amount of $\mathrm{Au}(\mathrm{III})-\mathrm{O}$ and possibly $\mathrm{Au}(\mathrm{I})-\mathrm{O}$ bonds is also present (approximately $70 \% \mathrm{Au}$ metal and $30 \% \mathrm{Au}$ oxides), thus suggesting that a gold-MgO interaction occurs. It is noteworthy that the frequency values of chemisorbed $\mathrm{CO}$, measured by ir (14), independently pointed to some effect of the support in R000.

R000 is a very active catalyst for the studied oxygen transfer reaction, its activity being two orders of magnitude higher than that of R100. Both R000 and R100 have a negative exponent $m$, i.e., the number of surface active centers decreases on increasing the oxidation power of the $\mathrm{CO}-$ $\mathrm{CO}_{2}$ mixture: this suggests that the ratedetermining step for reaction (I) could consist in the reaction of ${ }^{14} \mathrm{CO}_{2}$ with surface metal atoms (6). Therefore, metal-support interactions (like that suggested by EXAFS analysis for $\mathrm{R}(000)$ could have a determining influence on the catalytic activity. As for the lower activity of $\mathrm{R} 100$ with respect to R000, it could be due to the blocking of Ru surface sites by strongly chemisorbed $\mathrm{CO}$ and/or $\mathrm{CO}_{2}$ species.

The DR spectra of R047, R061, and R064 are different from those of the monometallic samples (also before reduction) and are not their simple superpositions. This suggests the existence of a reciprocal influence of the two elements already in the first steps of the catalyst preparation. It could be a simple interaction in the solution and/or the presence of the one compound could eventually affect the interaction of the other with the support.

Coming to the reduced bimetallic catalysts, the following short summary of the results obtained in the ir study (14) on some of these samples will be of help for the discussion:

(a) the spectrum of $\mathrm{CO}$ chemisorbed on R089 was similar to that obtained on R100;

(b) R064 gave a spectrum characteristic of unreduced ruthenium adsorption sites, even after pretreatment conditions sufficient for a complete reduction of $\mathrm{R} 100$;

(c) no evidence was found for the existence of $\mathrm{Au}$ on the surface of R089 and R064;

(d) the spectrum of $\mathrm{CO}$ adsorbed on R010 showed the presence of both $\mathrm{Au}$ and $\mathrm{Ru}$ on the surface;

(e) the position of the $\mathrm{CO}-\mathrm{Au}$ band on R010 was higher by 10 to 15 wavenumbers than on R000.

The surface analysis by XPS and the ir data (item (c) of the above summary) strongly suggest the existence of a surface Ru enrichment. Thus, according to the socalled "cherry" model, previously described by Sachtler and Jongepier (33) for the $\mathrm{Cu}-\mathrm{Ni}$ system, bimetallic $\mathrm{Ru}-\mathrm{Au}$ particles are probably formed and $\mathrm{Ru}$ atoms occupy the outermost layers. It is noteworthy that the less volatile metal $(\mathrm{Ru})$ prevails on the surface of these $\mathrm{Ru}-\mathrm{Au} / \mathrm{MgO}$ samples; in both supported and unsupported $\mathrm{Ru}-\mathrm{Cu}$ catalysts, the more volatile $\mathrm{Cu}$ was shown instead to cover the Ru clusters ( $I-$ 3, 34-36). Some specific effect of the $\mathrm{MgO}$ support on the particles' nucleation and/or growth could be a possible explanation of the different behavior of our catalysts, but this point requires further investigation. The ruthenium surface enrichment is consistent with the chemisorption and catalytic activity data. In fact, the fraction of $\mathrm{Ru}$ atoms exposed on the catalyst surface was found to increase on decreasing the bulk $\mathrm{Ru} / \mathrm{Au}$ atomic ratio, and no increase in the catalytic activity of the bimetallic samples was found on increasing the gold content (even though $\mathrm{Au} / \mathrm{MgO}$ is much more active in reaction (I) than $\mathrm{Ru} / \mathrm{MgO}$ ).

Some other results of the chemicophysical characterization of the $\mathrm{Ru}-\mathrm{Au} / \mathrm{MgO}$ catalysts suggest the existence of an inter- 
action between the two metals; besides the ruthenium surface segregation. Thus, EXAFS analysis shows that the amount of oxidized ruthenium is significantly larger in R064 than in R100, in agreement with the incomplete reduction of the metal found by ir (item (b)). Similarly, only Au-Au bonds are found by EXAFS in R064, while in R000 about $30 \%$ of the Au atoms are bound to the oxygen atoms of the support. Also the trend found in the DRS spectra of the reduced bimetallic catalysts (R010: maximum at about $540 \mathrm{~nm}$, like R000; R047, $\mathrm{R} 061$, and R064: broad maxima in the range 600-1000 nm; R089: broad maximum beyond $1200 \mathrm{~nm}$, like R100) suggests that some chemical interaction occurs, possibly affecting the nature of the species present in that surface layer examined by this technique. Finally, the $\mathrm{Au}-\mathrm{CO}$ bands found for sample R010 are shifted with respect to those of R000 (ir results, item (e)), the presence of even small amounts of ruthenium significantly affects the gold surface sites.

Only sample R010 requires a more detailed discussion. In fact, R010 has a relatively low Ru content, while the Au analytical concentration is higher than that of R000. Thus, the surface concentration of ruthenium in R010 is below the XPS sensitivity, while that of gold is approximately equal in R010 and R000. Furthermore, Au$\mathrm{CO}$ bands (which were not observed in R089 and R064) are found by ir (item (d)) in R010. Therefore, it appears difficult to justify the catalytic behavior of R010 with respect to $\mathrm{R} 000\left(k_{\mathrm{c}}^{0}=0.62\right.$ and 110.45 , respectively, at $290^{\circ} \mathrm{C}$ ) only on the basis of a ruthenium surface enrichment. This again supports the existence of an $\mathrm{Ru}-\mathrm{Au}$ interaction.

Both catalytic and ir data show gold in sample R010 to be more similar to $\mathrm{Au} / \mathrm{SiO}_{2}$ than to $\mathrm{Au} / \mathrm{MgO}(\mathrm{R} 000)$. In fact, the activity of $\mathrm{Au} / \mathrm{SiO}_{2}(\bar{d}=85 \AA)$ is three orders of magnitude lower than that of $\mathrm{Au} / \mathrm{MgO}$ in the oxygen transfer between $\mathrm{CO}$ and $\mathrm{CO}_{2}$ (10), while the stretching frequency value of CO chemisorbed on R010 (2100-2110 $\mathrm{cm}^{-1}$, depending on the pretreatment conditions (14)) is near to that found on $\mathrm{Au} / \mathrm{SiO}_{2}$ (37). It therefore seems that the presence of even small amounts of $\mathrm{Ru}$ can somehow affect or counterbalance the interaction between gold and support, so that gold of R010 behaves as if it were supported on silica. On the basis of the available data, however, it is not possible to explain how this occurs.

\section{CONCLUSIONS}

The main conclusions which can be drawn from the present work are:

(a) ruthenium and gold, which are practically immiscible in the bulk state, form bimetallic aggregates when dispersed on $\mathrm{MgO}$; furthermore, some reciprocal $\mathrm{Ru}-\mathrm{Au}$ influence seems to occur already before reduction;

(b) the surface of these bimetallic clusters is enriched in $\mathrm{Ru}$.

Item (a) recalls the results found by $\mathrm{Sin}$ felt et al. $(1-4)$ for the $\mathrm{Ru}-\mathrm{Cu}$ and Os-Cu systems. Item (b) instead points out a peculiar behavior of our $\mathrm{Ru}-\mathrm{Au} / \mathrm{MgO}$ catalysts. In fact, in bimetallic systems of the VIII and $\mathrm{Ib}$ groups, the Ib-group metal is generally found (in the absence of a strong chemisorption) to segregate at the surface. This is generally explained by the different sublimation heat and/or surface tension. In our case, however, other factors have to be considered. It seems possible that the surface composition is determined by the nature of the $\mathrm{MgO}$ support, by the preparative conditions, and, more generally, by all of those parameters which can affect the rate of nucleation and/or growth of the metal particles. To investigate these points, further work on the $\mathrm{Ru}-\mathrm{Au}$ system is in progress.

\section{ACKNOWLEDGMENTS}

The authors are grateful to Mr. R. Armstrong, Mr. W. Cavigiolo, Dr. T. Fukushima, Mr. W. Grazioli, Mr. L. Pozzi, and Mr. D. Volo for help in the experimental work; to Dr. N. Bottazzini and Mr. L. Fenoggio for chemical analysis; and to Mr. A. Orlandi for TEM measurements. S.G. acknowledges with thanks the financial support of Montedison S.p.A. and of the 
National Science Foundation through Grants ENG 75 14193 and CHE 76-11255. G.C. acknowledges the financial support of the Italian C.N.R.

\section{REFERENCES}

1. Sinfelt, J. H., J. Catal. 29, 308 (1973).

2. Sinfelt, J. H., Lam, Y. L., Cusumano, J. A., and Barnett, A. E., J. Catal. 42, 227 (1976).

3. Helms, C. R., and Sinfelt, J. H., Surface Sci. 72, 229 (1978).

4. Sinfelt, J. H., and Cusumano, J. A., in "Advanced Materials in Catalysis" (J. J. Burton and R. L. Garten, Eds.). Academic Press, New York, 1977.

5. Rudnitskii, A. A., and Novikova, O. A., Russ. J. Inorg. Chem. 4, 722 (1959).

6. Cha, D. Y., and Parravano, G., J. Catal. 18, 200 (1970).

7. Parravano, G., J. Catal. 18, 320 (1970).

8. Galvagno, S., and Parravano, G., J. Catal. 55, 178 (1978).

9. Galvagno, S., and Parravano, G., J. Catal. 57, 272 (1979).

10. Galvagno, S., and Parravano, G., Ber. Bunsenges. Phys. Chem. 83, 894 (1979).

11. Bassi, I. W., Lytle, F. W., and Parravano, G., J. Catal. 42, 139 (1976).

12. Cocco, G., Enzo, S., Fagherazzi, G., Schiffini, L., Bassi, I. W., Vlaic, G., Galvagno, S., and Parravano, G., J. Phys. Chem. 83, 2527 (1979).

13. Fukushima, T., Galvagno, S., and Parravano, G., J. Catal. 57, 177 (1979).

14. Schwank, J., Ph.D. thesis, Innsbruck, Austria, 1977; Schwank, J., Parravano, G., and Gruber, H. L., J. Catal. 61, 19 (1980).

15. Theriault, G. E., Barry, T. L., and Thomas, M. J. B., Anal. Chem. 47, 1492 (1975).

16. Scofield, J. H., J. Electron Spectrosc. Relat. Phenom. 8, 129 (1976).

17. Lytle, F. W., Sayers, D. E., and Stern, E. A., Phys. Rev. B 11, 4825 (1975).

18. Lytle, F. W., Sayers, D. E., and Stern, E. A., Phys. Rev. B 11, 4836 (1975).
19. Wyckoff, R. W. G., "Crystal Structures," Vol. 1. Interscience, Publ. Inc. New York, 1960.

20. Baman, C. E., Acta Chem. Scand. 24, 116 (1970).

21. Klug, H. P., and Alexander, L. E., "X-ray Diffraction Procedures for Polycrystalline and Amorphous Materials," pp. 637-642. Wiley, New York, 1974.

22. Fagherazzi, G., Maggi, C. M., and Sironi, G., Ceramurgia 2, 181 (1972).

23. Kratky, O., Pilz, P. J., and Schmitz, P. J., J. Colloid Interface Sci. 21, 24 (1966).

24. White, T. E., Kirklin, P. W., Gould, R. W., and Heinemann, H., J. Catal. 25, 407 (1972).

25. Renouprez, A., Hoang-Van, C., and Compagnon, P. A., J.Catal. 34, 411 (1974).

26. Fagherazzi, G., Cocco, G., Schiffini, L., Enzo, S., Benedetti, A., Passerini, R., and Tauszik, G. R., Chim. Ind. (Milan) 60, 892 (1978).

27. Bottazzini, N., Fenoggio, L., and Gozzi, A., Montedison Int. Rep. AM 11/77 (1977).

28. Batista-Leal, M., Lester, J. E., and Lucchesi, C. A., J. Electron Spectrosc. Relat. Phenom. 11, 333 (1977).

29. Taylor, K. C., J. Catal. 38, 299 (1975).

30. Bossi, A., personal communication.

31. Grabke, H. J., Ber. Bunsenges. Phys. Chem. 71, 1067 (1967).

32. Bossi, A., Garbassi, F., Orlandi, A., Petrini, G., and Zanderighi, L., in "Preparation of Catalysts II' (B. Delmon, P. Grange, P. Jacobs and G. Poncelet, Eds.), p. 405. Elsevier, Amsterdam/New York, 1979.

33. Sachtler, W. M. H., and Jongepier, R., J. Catal. 4, 665 (1965).

34. Lytle, F. W., Via, G. H., and Sinfelt, J. H., Prepr. Div. Petrol. Chem. Amer. Chem. Soc. 21(2), 366 (1976).

35. Bond, G. C., and Turnham, B. D., J. Catal. 45, 128 (1978).

36. Prestridge, E. B., Via, G. H., and Sinfelt, J. H., J. Catal. 50, 115 (1977).

37. Yates, D. J. C., J. Colloid Interface Sci. 29, 197 (1969). 